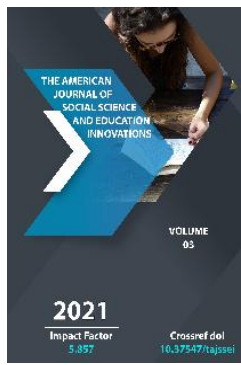

\section{The Use Of Tasks That Create A Tendency To The Problems Of Making Typical Mistakes In The Possession Of Graphic} Literacy

Ashirbaev Azim Ozodovich

Associate Professor Of Engineering And Computer Graphics, Tashkent State Pedagogical University Named After Nizami, Tashkent, Uzbekistan
Journal Website:

http://theamericanjour

nals.com/index.php/taj ssei

Copyright: Original content from this work may be used under the terms of the creative commons attributes 4.0 licence.

\title{
ABSTRACT
}

This article discusses typical mistakes made by students in graphic literacy and the use of methods and tasks that can be used to prevent them.

\section{KEYWORDS}

Graphic literacy, typical error, error-prone tasks, warning.

\section{INTRODUCTION}

Mistakes made by students in drawing and reading activities have a negative impact on the acquisition of graphic knowledge. The issue of prevention of various types of errors that occur for both objective and subjective reasons requires that it be studied and researched as a topical issue. This will encourage them to identify the causes, take preventive measures, develop early warning and remedial measures. This, in turn, contributes to the quality of graphic literacy in graphic education. Graphic literacy is not only the ability to draw and read diagrams correctly but also the level of knowledge of the student. The high level of literacy depends in all respects on the teachers of drawing, teaching aids and its theoretical and methodological support. In particular, training in the implementation of the requirements of the State Standard in a single system of design documentation, its provisions, their proper use in the implementation of graphic images in accordance with the requirements of the industry; to be able to independently perform graphic operations related to any imaging methods; to know the theoretical bases of graphic representation methods, to teach them to use them correctly, to use them correctly; the development and application of modern pedagogical technologies in the 
curriculum to update the content of education and, as a result, to improve the quality of graphic language teaching and to achieve literacy of students.

\section{MATERIALS AND METHODS}

In order for students to be perfectly literate in the field of graphic literacy, it is necessary to increase the level of functional literacy. To determine what this is, it is necessary to identify the types of functional illiteracy. That is the inability to comprehend graphic images; inability to critically perceive images; inability to draw incorrectly; not being able to read without mistakes; inability to describe or express without error; misunderstanding of graphic data; not knowing how to use tools, equipment and technical means, and not following a healthy lifestyle.

In graphic education, in addition to the study of theory, there are tasks and exercises. Tasks not only help students to apply the theory learned in production and practice, but also to develop a deeper understanding of the theory learned and thinking. Drawing also emphasizes the need for students to complete graphic assignments. There are several studies done in G.A. Ball. On problem solving and performance pedagogy that have been studied in detail [1].

Targeted activities such as graphic assignment, graphic problem, graphic work, graphic exercise and graphic task serve to compile and develop graphic literacy. In this regard, we compare the content of the concept of task and exercise with the content of the concept of task and exercise, noting that the content of the concept of task is broader than the content of the concept of exercise. In our work, too, when we use the phrase "task that creates a tendency to make mistakes," the content of the task concept is understood more broadly than the content of the exercise concept. The task can be difficult or simple: in the first case, it is difficult to find a solution, in the second - it easy. The difficulty of the task is part of the concept of the task: if there is no difficulty, there is no problem.

According to M.I. Zaykina, V.A. Kolosova's work in the field of mathematics "applies provocative tasks to all similar tasks that have conditions, instructions, or other motivators that encourage students to choose the wrong solution or wrong answer." is proposed as [2].

M.I. Zaikin [3], V.A. Kolosova [4] identified a variety of provocative tasks. Based on such scientific ideas and views in the field of mathematics in 1990-2009, today in the field of graphic education, using error-prone - errorprone tasks, a variety of misconceptions can occur. and serves as a methodological basis for the prevention of other types of errors. When warning-error-prone tasks are used in a lesson, "the student feels trapped and admits that the continuation of these actions will inevitably end in error. In this regard, the student is embarrassed, regretting that the continuation of the work he started is the result of a mistake, and he is embarrassed because he did not pay attention to the specifics of the situation".

This situation makes a strong impression on the student who made the mistake in front of his or her classmates or teacher, remembers the misbehaviours that have been made for a long time, and then a reflex that acts as a warning occurs to prevent errors.

As a result of the analysis of the literature of descriptive geometry, engineering graphics and other disciplines, the positive aspects of the use of graphical operations, which warn against mistakes in the performance of tasks, that is, the tendency to make mistakes. In this 
regard, it is recommended to create tasks that encourage reasoning with a hidden error that leads to a clear misconception.

Usually, the error in such a question corresponds to several parameters of the correct answer. Only some of the tricks that exist in it, in part, require attention, common sense, extreme vigilance and self-control. It is important to note that the regular use of a warning, error-prone tasks helps to avoid expected mistakes and to provide an in-depth study of the error and its analysis during the performance of the same type of tasks. The use of methods that cause similar problems has been considered by mathematicians I.Ya. Subbotin and M.S. Yakir, who have suggested the use of task blocks that cause errors. This, in turn, requires the development of risk factors. Therefore, tasks that cause errors include tasks that cannot be performed compared to other tasks, i.e., a "false direction", i.e., a false direction. This includes warnings at specific locations.

We believe that the concept of "warning task" should be defined through the concept of "task that creates a tendency to make mistakes". In the analysis of various dictionaries [5], it was found that the word "warning" means alert, alert, alert, meaning alert, alert and alert: warning is a treacherous behaviour, serious it is also emphasized in the sense of provocative actions that can lead to consequences. In medicine, the word is used to artificially induce or aggravate certain symptoms of a disease in order to cure it completely [6-11].

Based on the above interpretations of the term "error-prone task", we define the errorprone task. This involves encouraging students to make mistakes at one of the stages of the task by assigning a task that creates a tendency to make mistakes, thereby warning students not to make mistakes [1218].

\section{RESULTS}

Hence, tasks that are prone to error can be described on the basis of the name of the warning tasks. So, we can say that a warning task is a task that involves motivators to force them to do something wrong at one of the stages of solving it. Thus, the types of alert tasks depend on the type of alert. An analysis of the literature on stimulus tasks made it possible to distinguish the following types of warnings, that is, motivators who encourage misbehaviour or choose the wrong response. In this case:

1) The task is presented with a sketch containing the error.

2) A set of tasks that lead to the use of incorrect similarities in the performance of a task.

3) The task has an ambiguous solution.

4) Use puns: is that right? Is it possible to do that? ..?

5) Includes conflict of interest.

6) The answers suggested for the task include some correct answers or do not include the correct answer. Thus, the warning may include:

1) With students understanding the task text.

2) By creating a task plan for students.

3) By studying the solution of the problem.

So, in short, each type of warning is designed to prevent a specific type of error.

These types of warnings help prevent errors, especially typical ones, that can occur when performing graphical tasks. 
REFERENCES

1. Ball, G.A. (1990). B20 Theory of educational tasks: Psychological and pedagogical aspect. M.: Pedagogy, 1990. $184 \mathrm{p}$.

2. Zaikin, M.I., \& Kolosova, V.A. (1997). Challenging tasks. Mathematics at school, (6), 32-36.

3. Kolosova V.A. (1997). Improvement of the system of methodical work by mathematical mistakes of schoolchildren: dis. ande. ped. Sciences: 13.00.02 / Kolosova Vera Anatolyevna. Arzamas ,. 148 p.

4. Annotated dictionary of the Uzbek language. Edited by A.Madvaliev. 80,000 words The letter "O" 72 pages.

5. Ashirbaev, A., Ergashev, T., \& Tillaeva, D. (2019). Typical Mistakes that Occur in the Process of Learning to Draft. International Journal of Progressive Sciences and Technologies, 17(1), 294296.

6. Valiev, A. (2021). About the features of the perspective of simple geometric shapes and problems in its training. Zbírnik naukovix prats SCIENTIA.

7. Malikov, K. G. (2020). Theory and practice of construction of axonometric projects. European Journal of Research and Reflection in Educational Sciences Vol, 8(9).

8. Xalimov, M., \& Farxodova, Z. (2021). Developing students creative abilities by making the problem-solution situation in drawing subject. Збірник наукових праць $\Lambda$ ОГО $\Sigma$.

9. Axmedov, J. (2021). The development of landscape architecture in uzbekistan. Збірник наукових праць SCIENTIA.

10. Gafurovich, M. K. (2021). Axonometry New Practical Graphical Methods For Determining System Parameters.
Psychology and Education Journal, 58(2), 5710-5718.

11. Saydaliyev, S., \& Gulomova, N. (2019). Development of Spatial Thinking of Students Based on the Traditions of Eastern Architecture. International Journal of Progressive Sciences and Technologies, 14(2), 210-214.

12. Gulomova, N. (2021). Use of interactive methods for students in teaching drawing lessons (on the example of views). Academicia: an international multidisciplinary research journal, 11(1), 1637-1642.

13. Gulomova, N., \& Saidaliyev, S. (2020). Development of Emergency Image in Students Psychological-Pedagogical Problems. International Journal of Progressive Sciences and Technologies, 18(2), 181-186.

14. Tashimov, N. E., Student, M., Zoitov, S., \& Oblakulova, L. (2019). Methods of development and application in the educational process of computer technology in teaching graphic disciplines. European Journal of Research and Reflection in Educational Sciences Vol, 7(12).

15. Alimovich, N. E. (2021). Determination Of General Positions For The Solution Of Geometric Tasks. International Journal of Progressive Sciences and Technologies, 25(2), 237-241.

16. Jabbarov, R. (2021). Developing students 'creative abilities through teaching "Landscape color picture" in higher education system. Конференции, 1(1).

17. Jabbarov, R., \& Rasulov, M. (2021). Further formation of students' creative abilities by drawing landscapes in painting. 3бірник

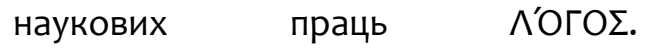


The American Journal of Social Science and Education Innovations (ISSN - 2689-100x)

Published: June 28, 2021 | Pages: 99-103

Doi : https://doi.org/10.37547/tajssei/Volume03Issueo6-16

https://doi.org/10.36074/logos-

30.04.2021.v2.09.

18. Jabbarov, R. (2021). Priorities for the development of painting. Конференции, 1(1). https://doi.org/10.47100/conferences.v 111.952. 